\title{
PREDISPOSITION TO THROMBOPHILIA AND HYPOFIBRINOLYSIS IN PULMONARY EMBOLISM: ANALYSIS OF INHERITED FACTORS
}

\author{
Regina Komsa-Penkova, \\ Pencho T. Tonchev', \\ Katya S. Kovacheva ${ }^{2}$, \\ Galya B. Georgieva, \\ Yavor Y. Ivanov ${ }^{3}$, \\ Petar D. Ivanov, \\ Georgi M. Golemanov, \\ Sergey D. Iliev ${ }^{1}$
}

\author{
Department of Chemistry and \\ Biochemistry, \\ Physics and Biophysics, \\ Medical University - Pleven \\ ${ }^{1}$ Clinic of Surgery, \\ Univeristy Hospital "Dr. Georgi \\ Stranski” \\ ${ }^{2}$ Section of Medical Genetics, \\ Medical University - Pleven \\ ${ }^{3}$ University Lung Diseases Hospital, \\ Medical University, \\ Pleven, Bulgaria
}

\author{
Corresponding Author: \\ Regina Komsa-Penkova \\ Department of Chemistry and \\ Biochemistry, \\ Physics and Biophysics, \\ Faculty of Medicine, \\ Medical University - Pleven \\ 1, Kliment Ohridski str. \\ Pleven, 5800 \\ Bulgaria \\ e-mail: rkomsa@gmail.com
}

Received: July 01, 2013

Revision received: December 09, 2013

Accepted: December 27, 2013

\begin{abstract}
Summary
Pulmonary embolism (PE) is a relatively common cardiovascular emergency, though its exact incidence is difficult to assess. Accurate diagnosis is critical because of the high 30-day mortality in patients in whom the diagnosis is missed on admission. Doubt for PE is often raised by the presence of risk factors for venous thromboembolism (VTE), which are categorized into inherited and acquired. Among these, the importance of inherited/genetic thrombophilic factors is increasingly recognized. The most frequent markers of inherited thrombophilia are Factor V Leiden (FVL) and G20210A prothrombin gene mutation. Among the inherited factors causal to thrombophilia, the $\mathrm{C} 677 \mathrm{~T}$ variant in methylentetrahydrofolate reductase (MTHFR) gene as well as factors like P1A1/P1A2 polymorphism in platelet glycoprotein IIb/IIIa (P1A2) and hypofibrinolytic polymorphism $4 \mathrm{G} / 4 \mathrm{G}$ in PAI-1 gene are discussed with controversial results. In our study, thrombophilic and hypofibrinolytic genetic variants were identified in $54.2 \%$ of 115 patients with PE. The most common significant genetic defects were FVL- $16.5 \%$ in patients versus $6.2 \%$ in controls $(\mathrm{OR}=3.102 ; \mathrm{p}=0.05), \mathrm{G} 20210 \mathrm{~A}$ PT $5.7 \%$ versus $2.1 \%(\mathrm{OR}=2.983 ; \mathrm{p}>0.05) . \mathrm{PlA} 2$ was found in $27.3 \%$ patients versus $19.9 \%$ in controls $(\mathrm{OR}=1.523$, $\mathrm{p}>0.05)$ and PAI-1 $27.8 \%$ versus $22.6 \%(\mathrm{OR}=1.501$ $\mathrm{p}>0.05)$. MTHFR C677T carriage was inverse: $6.7 \%$ in patients versus $13.4 \%$ in controls. $(\mathrm{OR}=0.461 \mathrm{p}=0.05)$. Of all the patients studied, $15.65 \%$ had a history of recurrent embolic incidents. The risk of recurrence was higher for the carriers of FVL and G20210A prothrombin gene mutation. The association between carriage of thrombophilic genetic factor and the early onset of the first embolic episode was found in the patients with PE. The awareness of risk factors and risk stratification is a critical issue in treatment and prevention policy. Preventive measures should be taken in particular medical conditions.
\end{abstract}

Key words: thrombophilia, hypofibrinolysis, FVL, PTA G20210A, MTHFR, GLPR IIb/IIIa, PAI-1, pulmonary embolism

\section{Introduction}

Pulmonary embolism (PE) is a relatively common cardiovascular life-threatening disease. Accurate diagnosis is critical because of the high 30-day mortality in patients in whom the diagnosis is missed 
on admission. Guidelines propose the methodology and approaches for the best diagnostic procedures [1]. Previous studies have shown that, if left untreated, its mortality could reach approximately $20-30 \%$ while appropriate treatment decreases it to $5 \%[2,3]$. Despite the great number of publications, there is still no consensus regarding the optimal diagnostic approach, as the event is often "atypical", and signs and symptoms are usually vague and nonspecific [4]. Table 1 lists the most common risk factors associated with VTE. Previous studies on VTE have stated that at least one risk factor was found in $80 \%-96 \%$ of patients with proven VTE disease [5].

The proportion of patients with idiopathic or unprovoked PE was about $20 \%$ in the International Cooperative Pulmonary Embolism Registry (ICOPER) [6]. However, in younger patients this proportion was as low as $28 \%$ [7]. VTE is considered to be a multifactorial disease caused by environmental and genetic risk factors, as well as by some medical conditions that interact dynamically.

Recently, gene polymorphisms have received an increasing attention. An inherited hypercoagulability should be suspected in patients who have had a VTE event (documented) at a younger age $(<40)$ or have a family history of thrombosis.

The impact of genetic factors in PE development is recognised in Pulmonary British Guidelines [8]. However, there is no recognized role, nor are there clear guidelines for the DNA testing in subjects with suspected PE. This impedes accurate diagnosis and treatment strategy.

Table 1. Risk factors for Venous Thromboembolic Disease

\begin{tabular}{lllll}
\hline \multicolumn{2}{c}{ Non-modifiable factors: } & & Modifiable factors: & \\
\hline & Inheritance & Lifestyle & Clinical parameters & Medical conditions \\
\hline Age & Factor V Leiden & Tobacco smoking & Malignancy & Congestive heart \\
Personal history of & Prothrombin 20210A & Weight gain/obesity & Trauma & failure \\
venous & mutation & Sedentary life/ & Surgery & Nephrotic syndrome \\
thromboembolism & Protein C deficiency & long flights & Pregnancy & Myocardial infarction \\
Family history & Protein S deficiency & & Central venous & Stroke \\
& Antithrombin III & & catheters & Crohn's disease \\
& deficiency & Immobilization & \\
& Plasminogen deficiency & & Hormone replacement & \\
& PAI 1 4G/4G & therapy & \\
& Factor XII deficiency & Lupus anticoagulant/ & \\
& Hyperhomocysteinemia & anticardiolipin antibody & \\
& Dysfibrinogemia & & &
\end{tabular}

\section{Hereditary thrombophilia}

Factor $V$ Leiden is the most common thrombophilic inherited disorder. It has been reported with a prevalence as high as $20 \%$ in patients with VTE [9]. Its contribution is up to $50 \%$ in selected patients with a family history of thrombophilia [10]. A transition in guanine to adenine at 1691 position (G1691A) leads to production of factor $\mathrm{V}$ protein $(\mathrm{FVL})$ resistant to the action of activated protein C (APC). FVa is suggested as a cofactor of protein $\mathrm{S}$ contributing to degradation of FVIIIa by APC. Lack of FVa decreases the activity of APC. FVL is a common mutation that is present in $4 \%$ to $6 \%$ of the general population.

Prothrombin G20210A mutation (PTM) represents the second most important prothrombotic mutation. In subjects with a history of venous thromboembolism it ranges from about $5 \%$ to $15 \%$, reaching up to $20 \%$ in selected patients with familial thrombophilia [11, 12]. In Caucasians the prevalence of the G20210A allele is about 2.3\% among healthy carriers, and about $6.2 \%$ among VTE patients.

Heterozygous carriers have 30 percent higher plasma prothrombin levels as compared to controls. Prothrombin (factor II) possesses procoagulant, anticoagulant and antifibrinolytic activities [13]. That is why this polymorphism results in multiple imbalances in hemostasis. Heterozygotes have a 2 to 5 -fold higher risk of thrombosis [14].

The homozygous form (TT) of C677T point mutation in the methylentetrahydrofolate reductase (MTHFR) gene and its impact on 
hyperhomocystinemia related to PE development have been reported with conflicting results $[14$, 15]. The genetic variants C677T in MTHFR produce a thermostable and less active enzyme, which leads to a slower metabolism of methionine, related mutilations and homocysteine (Hcy) [16]. TT homozygotes for C677T have approximately a $70 \%$ reduction of normal MTHFR enzyme activity and heterozygotes have approximately a $40 \%$ reduction of normal enzyme activity.

Recently, hyperhomocystinemia related to homozygous form of mutation C677T in the gene for MTHFR has been recognized as an independent risk factor for venous thrombosis, particularly in combination with deficiency of folic acid, vitamin B12 and B6. Variant C677T of MTHFR is very common and is present in the homozygous form in $5-15 \%$ of the population $[17,18]$.

Two other genetic variants - PlA1/PlA2 polymorphism in platelet glycoprotein IIb/IIIa (PlA2) and hypofybrilic PAI-1 4G/4G have also been associated with an incidence of venous thrombosis, as they change blood clotting/fibrinolysis process.

PIA2 polymorphism in platelet glycoprotein GP IIb/IIIa, being a critical element of the clot formation process was discussed as a possible inherited factor of prothrombotic tendency. The prevalence ranges from $14.5 \%$ [19] to $31.6 \%$ [20] in VTE patients. In the general population, most frequent values of polymorphism carriage vary between 10 and $25 \%$. Nonetheless, a controversy exists as to whether this genetic variation can contribute to the susceptibility of P1A2 allele carriers to thrombotic events.

Plasminogen activator inhibitor-1 (PAI-1) is an important regulatory molecule of the fibrinolytic pathway. PAI-1 binds to tissue plasminogen activator (tPA), and by inhibiting conversion of plasminogen to plasmin leads to decreased fibrinolysis. High levels of PAI-1 may be associated with a risk of thrombosis due to the inhibition of fibrinolysis [21].

Although several studies have suggested a contribution of the $6754 \mathrm{G} / 5 \mathrm{G}$ variant in myocardial infarction development, very few data are available on the connection between PAI1 polymorphisms and the occurrence of VT [22].

Thrombophilia is considered as a multifactorial disease. It could be caused by several dynamically interacting inherited and/or acquired factors, including a coinheritance of two or more gene defects.

The set of environmental risk factors and coexisting factors was published in International Cooperative Pulmonary Embolism Registry (ICOPER) study. The key acquired risk factors for PE were as follows: DVT (49.3\%), obesity $(29.2 \%)$, surgery $(28.9 \%)$, bed rest $(28.1 \%)$ and previous PE $(24.9 \%)$.

Regardless of the progress in the investigation of the role of these factors as single and/or as cosegregated in the development of thrombosis and related diseases, their impact on the progression of venous thromboembolia and of $\mathrm{PE}$ in particular, as well as on the recurrence of episodes remains debatable.

We present our investigation on the incidence of the variant alleles of FVL, G20210A PTM, C677T MTHFR and P1A2, (PAI-1) 4G/5G; and their association with the onset and recurrence of episodes in PE patients.

\section{Materials and Methods}

\section{Selection of Patients and Study protocol}

A study was conducted at Pulmonology Department of University Hospital (Pleven, Bulgaria) from 2008 to 2013. A total of 115 unrelated patients with $\mathrm{PE}$ and 94 control subjects (age and sex adjusted) were investigated. The median age of the patients was 47.51 years (range 14 to 79 years).

The selection criterion was a history of one or more episodes of VTE and/or PE. PE was diagnosed by ventilation-perfusion lung scan, according to criteria set by British Thoracic Society. Deep venous thrombosis (DVT) was diagnosed by compression ultrasonography and Doppler ultrasonography. There were no patients with malignant or myeloproliferative diseases or systemic infections in the study group. Six out of a total of 53 investigated women had a history of obstetric complications: recurrent spontaneous abortions in the first and/or second trimester.

\section{Data Collection}

A specific questionnaire was used to interview patients with embolic incidence. The survey listed number and type of vascular incidents, age at onset of the first episode, number of recurrent episodes, family history, previous and present anticoagulation therapy, presence of risk factors such as surgery, trauma, immobilization, oral 
contraceptive use, pregnancy or postpartum period within the last 3 months.

Both patients and control groups were of similar demographic data and from the same geographical area. The study protocol was approved by the ethics commission of Medical University-Pleven, Bulgaria. All investigated subjects gave written informed consent for the investigation.

\section{Sample collection and DNA analysis}

Venous blood was collected in vacutainers with $0.084 \mathrm{ml} \mathrm{15 \%}$ EDTA (Becton, Dickinson and Company). DNA was isolated following the procedure of GFTTM Genomic Blood DNA Purification Kit (Amersham Pharmacy Biotech Inc) and quantified using the agarose gel procedure.

Polymerase Chain Reaction (PCR) was performed in a total volume of $20 \mu \mathrm{l}$ containing the following: $1 \mu \mathrm{l}(100 \mathrm{ng} / \mu \mathrm{l})$ genomic DNA, 0.4 $\mu \mathrm{l}(20 \mathrm{pmol} / \mu \mathrm{l})$ of respective forward and reverse primer, $1.8 \mu \mathrm{l}(5 \mathrm{mmol} / \mu \mathrm{l})$ deoxynucleotide triphosphates, $\mathrm{MgCl} 25 \mathrm{mmol} / \mu \mathrm{l}, 2.0 \mu \mathrm{l}, 2.0 \mu \mathrm{l}$ Buffer for Taq polymerase and Taq polymerase 1 U per sample (AB gene).

The amplification was carried out in a thermal cycler (Techne, version 11.04). The primers and reaction conditions for the investigated genetic defects have been described in earlier publications [23].

PCR products were fractionated by electrophoresis through $2.5 \%$ agarose (AppliChem) and visualized in UV light by ethidium bromide staining $(10 \mathrm{mg} / \mathrm{ml}, 10 \mu \mathrm{l})$.

The amplified samples $(10 \mu \mathrm{l})$ were incubated at $37^{\circ} \mathrm{C}$ for 12 hours with a specific enzymerestrictase (3U per sample), in the presence of $0.2 \mu 1$ Bovine serum albumin (Purified BSA 10 $\mathrm{mg} / \mathrm{ml}$ - New England BioLabs Inc) and $2 \mu 1$ NEB Buffer 2 (New England BioLabs Inc) in a total volume of $20 \mu 1$.

A specific restrictase was used for each mutation:

FVL - Mnl I (5000 U/ml); PTM G20210 Hind III (20 $000 \mathrm{U} / \mathrm{ml})$; MTHFR C677T - Hinf I (10 $000 \mathrm{U} / \mathrm{ml})$; PlA2 in GLPR IIb-IIIa - Msp I (20 $000 \mathrm{U} / \mathrm{ml})$; (New England BioLabs Inc).

The products of restrictase reaction were separated by electrophoresis over 3.5\% agarose gel and visualized in UV light by ethidium bromide staining $(10 \mathrm{mg} / \mathrm{ml}, 10 \mu \mathrm{l})$.

Allele specific PCR was used to detect $4 \mathrm{G}$ and $5 \mathrm{G}$ genotypes. Amplification was performed in two separate series, with the two constitutive primers and two inner primers corresponding to sequences $4 \mathrm{G}$ and $5 \mathrm{G}$ [24], and $270 \mathrm{bp}$ and 170 bp products were separated on 3\% agarose gel.

Visualisation with UV light was performed in ethidium bromide staining. PCR guidelines were strictly followed to avoid contamination. Sample collection, DNA isolation and quantitation were performed in the laboratory room, separated from the laboratory where sample amplification and analysis were performed [25].

\section{Statistical analysis}

Allele frequencies were calculated for each subgroup of patients and controls. Statistical Package for Social Sciences (SPSS) version19.0.was used. Statistical significance was taken at $\mathrm{p}<0.05$.

Due to the heterogeneity in the group of the patients with pulmonary embolism, the construction of the control group was not a simple process and there was a risk of mistake in the selection. To verify compliances between the groups in age and gender, an appropriate statistical methods was necessary. The control group included 94 unrelated healthy individuals (53 men and 41 women) with no family history of venous thrombosis and/or embolism. There was no statistically significant difference between the groups by gender, as evaluated by Fisher exact test $p=0.92$. There was no statistically significant difference between the groups in age - Student t- test, $\mathrm{p}=0.293$.

\section{Results}

A total of 115 patients with VTE and 94 control subjects were tested for the variant alleles of FVL, G20210A PTM, C677T MTHFR, PlA2 $\mathrm{IIb} / \mathrm{III}$ and PAI-1 4G/5G. The characteristics of the patients are presented in Table 2 . Respectively, the clinical parameters and life style factors were: surgery and trauma $(37.39 \%)$, immobilisation (18.26\%), obesity (25.21\%) and tobacco smoking $(26.95 \%)$. The results of DNA testing are presented in Table 3 . The overall number of mutation carriers was $62(53.91 \%)$ and double carriers were $14(12.17 \%)$.

\section{Onset of VTE}

The median age at first embolic incident was 44.8 years. Eighteen $(15.65 \%)$ of all patients had a history of recurrent embolic incidents. The clinical presentation of the VTE depended 
largely on the underlying cause. In the absence of inherited risk factors, thrombosis occurred in the older subjects: $49.7 \%$ versus $42.5 \%$ in mutation carriers (shown already in a previous pilot study [26]), mainly in the context of modifiable factors, such as surgery and trauma, immobilisation, obesity and tobacco smoking. The average age of the clinical manifestation in the subjects with extrinsic factors only was around 47 years. After adjusting for mutation carriage and life style factors it reached 57 years.

Table 2. Characteristics of the patients $(n=115)$

\begin{tabular}{ll}
\hline Characteristics & $\begin{array}{l}\text { Value } \\
\text { numbers and percentages in brackets }\end{array}$ \\
\hline Age (years): Mean & 47.48 \\
& 45.19 male, 50.11 female \\
\hline Range (years) & $14-79$ \\
\hline Men & $62(53.9 \%)$ \\
\hline Women & $53(46.1 \%)$ \\
\hline Age of the first thrombotic incidence & 44.8 \\
\hline Diagnosis of DVT & $43.0($ males $), 47.6$ (females) \\
\hline Unexplained cough & $33(28.7 \%)$ \\
\hline Previous pulmonary embolism/deep vein thrombosis & $64(55.75 \%)$ \\
\hline Trauma or surgery & $18(15.65 \%)$ \\
\hline Immobilisation & $43(37.39 \%)$ \\
\hline Obesity & $21(18.26 \%)$ \\
\hline Tobacco smoking & $31(26.69 \%)$ \\
\hline Diabetes & $31(26.69 \%)$ \\
\hline Early pregnancy loss (female patients) & $9(7.41 \%)$ \\
\hline
\end{tabular}

\section{Prothrombotic mutations}

The prevalence of thrombotic mutations, as well as the percentage within group, Pearson Chi-
Square, Fisher's Exact Test, Odds Ratio and 95\% confidence interval are presented in Table 3.

Table 3. Prevalence of thrombophilic factors FVL, prothrombin G20210A (PTM), MTHFR C677T, P1A2 $\mathrm{IIb} / \mathrm{IIIa}$, and PAI-1 4G/4G in patients as compared to controls

\begin{tabular}{llllllll}
\hline $\begin{array}{l}\text { Statistical } \\
\text { values }\end{array}$ & $\begin{array}{l}\text { Prevalence } \\
\text { in patients } \\
\mathbf{\%}\end{array}$ & $\begin{array}{l}\text { Prevalence } \\
\text { in controls } \\
\mathbf{\%}\end{array}$ & $\begin{array}{l}\text { Percentage } \\
\text { within } \\
\text { group } \%\end{array}$ & $\begin{array}{l}\text { Pearson } \\
\text { Chi- } \\
\text { Square }\end{array}$ & $\begin{array}{l}\text { Fisher's } \\
\text { Exact } \\
\text { Test }\end{array}$ & $\begin{array}{l}\text { Odds } \\
\text { Ratio }\end{array}$ & $\begin{array}{l}\text { 95\%Confidence } \\
\text { Interval }\end{array}$ \\
\hline FVL & 16.5 & 6.2 & 69.0 & $7.770^{\mathrm{a}}$ & 0.005 & 3.102 & $1.357-7.094$ \\
\hline PTM & 5.7 & 2.0 & 70.0 & $2.654^{\mathrm{a}}$ & 0.096 & 2.983 & $0.755-11.789$ \\
\hline P1A2 & 27.3 & 19.9 & 53.2 & $2.038^{\mathrm{a}}$ & 0.100 & 1.523 & $0.855-2.676$ \\
\hline PAI 1 & 27.8 & 22.6 & 52.1 & 1.934 & 0.110 & 1.501 & $0.942-3.657$ \\
\hline MTHFR & 6.7 & 13.4 & 28.6 & $-3.253^{\mathrm{a}}$ & 0.050 & 0.461 & $0.195-1.087$ \\
\hline Total & 53.91 & 35.3 & 60.7 & $3.129^{\mathrm{a}}$ & 0.050 & 1.553 & $0.953-2.532$ \\
\hline
\end{tabular}

\section{Modifiable riskfactors}

Numerous modifiable factors trigger VTE. Modifiable /reversible factors, such as surgery or trauma (37.39\%), obesity (26.69\%), immobilization (18.26\%), smoking (26.69\%), estrogen therapy $(7 \%)$ and pregnancy-related problems $(11.32 \%)$ were associated with a significant risk of a pulmonary event in our study. 


\section{Discussion}

The contribution of FVL was significant. About $16.5 \%$ of the patients carried FVL as compared to the controls $(6.2 \%)$ with an odds ratio $3.1(95 \%$ CI; 1.357-7.094). In our investigation, $25 \%$ of mutation carriers had FVL mutation. Recent investigations have presented similar data on Factor V Leiden: carriage of FVL is associated with 3- to 7-fold increase of risk of a first episode of VTE $[27,28]$ with about $15-20 \%$ prevalence of FVL reported [29,30].

The patients carriers of FVL were at higher risk of recurrent thrombotic episode $\mathrm{RR}=1.879$ (95\% CI; 0.643-4.446; $\mathrm{p}>0.5)$. Conflicting reports have been published in the medical literature, whether this polymorphism increase the risk of recurrent VTE. However, a recent review on reports from 10 studies [31 ], involving 3104 patients with first VTE revealed that FVL was present in $21.4 \%$ of patients and associated with an increased odds of recurrent VTE of 1.41 (95\% CI; 1.14-1.75; $\mathrm{p}=0.08$ for heterogeneity).

The penetrance of homozygous carriage of FVL was stronger, the carriers had both recurrent episodes and DVT at unusual location. Of the FVL carriers, $75 \%$ had an additional precipitating environment factor. The clinical data on coprecipitation with other hypercoagulabilic or hypofibrinolytic factor presents the impact of FVL as more pronounced, supporting the idea of the multifactorial etiology of PE.

The prevalence of prothrombin G20210A mutation in our patients was about $5.7 \%$ (heterozygous) comparing to $2.0 \%$ in controls $\mathrm{OR}=2.654 \quad(95 \% \quad \mathrm{CI} ; \quad 0.755-11.789 ; \quad$-value $>0.05)$. There was no homozygous carrier of this mutation. The risk of recurrence was high: $\mathrm{OR}=$ 2.556 (95\% CI, 0.349-13.691) but not significant. The prevalence of prothrombin G20210A is reported to be about $7 \%$ [32].

PTM G20210A increases the risk by 2- to 3fold. The risk of recurrence is rather modest. The results reported are controversial: of the 4 highquality studies, only one found a significant increase in risk of recurrence associated with heterozygous carriage of the G20210A polymorphism $(\mathrm{OR}=2.4 ; 95 \% \mathrm{CI}, 1.3-4.7)$ [33].

PIA2 IIb/IIIa carriage was extended in $27.3 \%$ of patients as compared to $19.9 \%$ of the control group with $\mathrm{OR}=2,038$, and non significant, $\mathrm{p}$ - value $>0.05$, in the range of the data from other authors: $14.5 \%$ to $31.6 \%$ In spite of the comparatively high prevalence of this polymorphism, only one patient was homozygous. The impact of this mutation to the development of VTE and PE in particular is under discussion. The recurrent incidents were the same level as in the patients who were non carriers of thrombophilic mutation $(\mathrm{OR}=1.108$; $95 \%$ CI, $0.322-3.90$ ). In more than $75 \%$ of cases the patients had an additional precipitating environment factor. To understand the importance of this polymorphism we have to keep in mind that it affects platelet membrane glycoprotein IIb/IIIa, which is a member of the integrin family of adhesive molecules, by binding fibrinogen and von Willebrand factor, promotes platelet aggregation and as a consequence contributes to thrombogenesis.

The prevalence of plasminogen PAI-1 4G/4G allele was about $27.8 \%$ (heterozygous), as compared to $22.6 \%$ in the controls $(\mathrm{OR}=1.934$; $\mathrm{p}>0.05$ ). The contribution to recurrence was also insignificant $(\mathrm{OR}=1.365 ; 95 \%$ CI $0.371-4.743)$. PAI-1 was investigated as a fibrinolytic factor playing a critical regulatory role in a variety of pathologic processes, including inflammatory responses [34], heart and lung fibrosis [35], coronary artery disease, myocardial infarction [36], ischemic stroke [37], sepsis, and endometriosis. Although the results are disputable, these conditions are often associated with elevated gene expression both in patients with cardiovascular and metabolic disorders and for endometriosis, but not in healthy individuals. There are investigations confirming that carriage of $4 \mathrm{G}$ allele appears to increase the risk of venous thrombosis, particularly in subjects with other genetic thrombophilic defects [38]. However, investigations on the relationship of carriage of $4 \mathrm{G}$ and VTE are controversial, as far as the impact of allele $4 \mathrm{G}$ is concerned.

As for variant allele C677T MTHFR, there was an adverse relationship between polymorphism carriage and VTE events. The prevalence of this mutation in the patients was lower than in the controls, $6.7 \%$ and $13.4 \%$, respectively $(\mathrm{OR}=0.461$, $\mathrm{p}$-value 0.5$)$. There were no carriers of this mutation among the patients with recurrent events. That is why when considering the contribution of genetic disorders to the development of VTE events, the C677T MTHFR polymorphism could not be considered as 
rigorous. Extracting this mutation from pooled thrombophilic factors slightly reduces the impact of thrombophilic mutation on VTE development.

Recently, hyperhomocysteinemia has been widely discussed as a factor contributing to the development of both arterial and venous thrombosis. A C677T point mutation within the MTHFR gene is the most common genetic defect, which causes hyperhomocysteinemia. In turn, elevated homocysteine levels exert numerous vasotoxic effects on the endothelium, leading to endothelial cell dysfunction, platelet activation, thrombus formation and increased risk of thrombotic events. However, the contribution of MTHFR polymorphism to the development of episodes of PE was not established in this investigation. What is more, there was a paradox of inverse relationship of mutation carriage and VTE events.

Incidence of recurrent thromboembolic events in patients with inherited and modifiable risk factors

The prevalence of recurrent thrombothic events (two or more incidents) was $15.6 \%$ among the VTE patients with available medical records. Eleven of these patients $(61.0 \%)$ had at least one mutation, FVL and PAI-1 being the most frequently presented in 5 carriers. The mean age of the patients with recurrent events who carried at least one mutation was 48.2 years, as compared to those without mutation, which was significantly higher -55.2 years.

Although there is a great deal of controversy regarding the significance of factor $\mathrm{V}$ Leiden in increasing the risk of recurrent venous thrombosis $[39,40]$, our investigation indicated that the prevalence of carriage of FVL and prothrombin G20210A was more frequent in patients with recurrent VTE $(27.7 \%$ and $11.2 \%$, respectively) than among those who had had no recurrences (16.5\% and 5.6\%, respectively). The relative risk of occurrence was calculated in patients who had a thrombophilic mutation and then compared to that in the patients without mutation, that is in accordance with a relative risks of recurrence ranging about 2 to 4 discussed by Simioni et al. [41].

The most frequent modifiable factors associated with a significant risk of pulmonary event were surgery and/or trauma (37.39\%), obesity $(26.69 \%)$ and smoking $(26.69 \%)$. The contribution of obesity and smoking was the highest, when the group of surgery was divided form those with trauma.
Obese and smoking patients had the same risk of recurrence as the total group of the patients. The patients with surgery, trauma, immobilization were at a lower risk of recurrent events and underwent a standard therapy.

The results showed that the greater the triggering factor was, the lower the risk of recurrence after anticoagulant withdrawal. These results were similar to those reported by other authors [42]. The low risk of recurrence after postoperative VTE was presented in a study comparing various durations of anticoagulant therapy. Prandoni et al. [43] have shown that surgery and recent trauma or fracture are associated with a lower risk of recurrent VTE, as compared to unprovoked VTE (hazard ratio 0.36; 95\% CI; 0.21 to 0.62). Subsequent studies have confirmed that the risk of recurrent VTE is much lower among patients whose initial VTE is provoked by modifiable/reversible risk factors than among patients with thrombophilia.

\section{Conclusion}

- The early onset of PE was confirmed for thrombophilic mutation carriers

- Both FVL and prothrombin G2010A mutation carriage was related to a higher risk of recurrence

- PAI-1 4G and PLA2IIb/IIIa polymorphisms play a certain role in the development of VTE

- For variant allele C677T MTHFR there was an adverse relationship between polymorphism carriage and VTE event.

- Obese and smoking patients had the highest risk of VTE development among the patients with modifiable risk factors

- The association between thrombophilic genetic factors FVL, prothrombin G2010A, PLA2IIb/IIIa and hypofibrinolytic PAI-1 4G and PE confirms the significance of applying genetic testing in patients with $\mathrm{PE}$.

Physicians should be aware of risk factors and risk stratification for VTE development, particularly in certain medical situation, so as to avoid VTE development and recurrent events. Genetic testing in patients with thrombosis and VTE would allow prevention of recurrent thrombotic incidents in individuals with inherited predisposition. Genetic testing may benefit patients with inherited tendency to hypercoagulability and hypofibrinolysis and PE through various approaches: longer duration of anticoagulation therapy; preventive anticoagulation for high risk medical conditions and live 
situations; avoidance of predisposing risk factors with synergistic action, family testing [44], counselling etc. All these could contribute to lower incidence of VTE, and PE in particular.

\section{References}

1. Torbicki A, Perrier A, Konstantinides S, Agnelli G, Galiè N, Pruszczyk P, et al. Guidelines on the diagnosis and management of acute pulmonary embolism. The Task Force for the Diagnosis and Management of Acute Pulmonary Embolism of the European Society of Cardiology. Eu Heart J. 2008;29:2276-315.

2. Goldhaber SZ. Venous thromboembolism: epidemiology and magnitude of the problem. Best Pract Res Clin Haematol. 2012;25(3):235-42.

3. Anderson FA Jr, Wheeler HB, Goldberg RJ, Hosmer DW, Patwardhan NA, Jovanovic B, et al. A population-based perspective of the hospital incidence and case-fatality rates of deep vein thrombosis and pulmonary embolism: the Worcester DVT Study. Arch Intern Med. 1991; 151:933-8.

4. Goldhaber SZ, Hennekens CH, Evans DA, Newton EC, Godleski JJ. Factors associated with correct antemortem diagnosis of major pulmonary embolism. Am J Med. 1982;73(6):822-6.

5. Rodger M, Wells PS. Diagnosis of pulmonary embolism. Thromb Res. 2001;103(6):V225-38.

6. Goldhaber SZ, Visani L, De Rosa M. Acute pulmonary embolism: clinical outcomes in the International Cooperative Pulmonary Embolism Registry (ICOPER). Lancet. 1999;353:1386-9.

7. Dulicuek P, Maly J, Pesuavova L, Pecka M. Prevalence of inherited thrombophilia in young thrombosis patients from the East Bohemian region. Blood Coagul Fibrinolysis. 2002; 13(6):569-73.

8. British Thoracic Society Standards of Care Committee. Pulmonary Embolism Guideline Development Group. British Thoracic Society guidelines for the management of suspected acute pulmonary embolism. Thorax. 2003;58:470-84.

9. Rosendaal FR, Koster T, Vandenbrouck JP, Reitsma PH. High risk of thrombosis in patients homozygous for factor V Leiden (activated protein C resistance). Blood. 1995;85:1504-8.

10. Juul K, Tybjaerg-Hansen A, Schnohr P, Nordestgaard BG. Factor V Leiden and the risk for venous thromboembolism in the adult Danish population. Ann Intern Med. 2004;140:330-7.

11. Kalafatis M, Bertina RM, Rand MD, Mann KG. Characterization of the molecular defect in factor VR506Q. J Biol Chem. 1995;270:4053-7.

\section{Acknowledgement}

The study was conducted with financial support from Medical University - Pleven (Project 24/2013).

12. De Stefano V, Rossi E, Paciaroni K, Leone G. Screening for inherited thrombophilia: indications and therapeutic implications. Haematologica. 2002;87:1095-108.

13. Poort SR, Rosendaal FR, Reitsma PH, Bertina RM. A common genetic variation in the 3'untranslated region of the prothrombin gene is associated with elevated plasma prothrombin levels and an increase in venous thrombosis. Blood. 1996;88(10):3698-703.

14. Bezemer ID, Doggen CJ, Vos HL, Rosendaal FR. No association between the common MTHFR 677C-> T polymorphism and venous thrombosis: results from the MEGA study. Arch Intern Med. 2007;167(5):497-501.

15. Castro R, Rivera I, Blom H. J, Jakobs C, De Almeida I. T. Homocysteine metabolism, hyperhomocysteinaemia and vascular disease: an overview. J Inherit Metab Dis. 2006;29(1):3-20.

16. Toole JF, Malinow MR, Chambless LE, Spence JD, Pettigrew LC, Howard VJ, et al. Lowering homocysteine in patients with ischemic stroke to prevent recurrent stroke, myocardial infarction, and death. JAMA. $2004 ; 291: 565-75$.

17. Fermo I, D'Angelo SV, Paroni R, Mazzola G, Calori G, D'Angelo A. Prevalence of moderate hyperhomocysteinemia in patients with early onset venous and arterial occlusive disease. Ann Intern Med. 1995;123:747-53.

18. De Bree A, Verschuren WM, Bjørke-Monsen AL, Van der Put NM, Heil SG, Trijbels FJ, et al. Effect of the methylenetetrahydrofolate reductase $677 \mathrm{C}$ ->T mutation on the relations among folate intake and plasma folate and homocysteine concentrations in a general population sample. Am J Clin Nutr. 2003;77:687-93.

19. Ridker PM, Hennekens CH, Schmitz C, Stampfer MJ, Lindpaintner K. P1A1/A2 polymorphism of platelet glycoprotein IIIa and risk of myocardial infarction, stroke and venous thrombosis. Lancet. 1997;349: 385-58.

20. Renner W, Winkler M, Hoffmann C, Koppel H, Seinost G, Brodmann M, et al. The PlA1/A2 polymorphism of platelet glycoprotein IIIa is not associated with deep venous thrombosis. Int Angiol. 2001;20(2):148-51.

21. Francis C. Plasminogen activator inhibitor-1 levels and polymorphisms. Association with venous thromboembolism. Arch Pathol Lab Med. 2002; 126(11):1401-4 
Penkova R., et al. Predisposition to thrombophilia and hypofibrinolysis...

22. Tsantes AE, Nikolopoulos GK, Bagos PG, Rapti E, Mantzios G, Kapsimali V, et al. Association between the plasminogen activator inhibitor-1 4G/5G polymorphism and venous thrombosis. A meta-analysis. Thromb Haemost. 2007;97(6):90713.

23. Komsa-Penkova R, Kovacheva- Kotseva K, Angelova S, Savov A, Semionova M. Selected methods of DNA analysis and clinical applications. Pleven: MU-Pleven; 2004.

24. Ivanov P, Komsa-Penkova R, Ivanov Y, Ivanov I, Matkov O, Beshev L. [4G/5G polymorphism in the gene for plasminogen activator inhibitor-1 in patients it may be a deep vein thrombosis]. Moderna Medicina. 2009;60(1-2):35-9. [in Bulgarian].

25. Kwok S, Higuchi R. Avoiding false-positives with PCR. Nature. 1989;339:237-8.

26. Ivanov $\mathrm{P}$, Komsa-Penkova $\mathrm{R}$, Kovacheva $\mathrm{K}$, Ivanov $\mathrm{Y}$, Stoyanova A, Ivanov I, Pavlov $\mathrm{P}$, Glogovska P, Nojarov V. Impact of genetic factors on pulmonary embolism - early onset and recurrent incidences. Lung. 2008;186(1):27-36.

27. Ridker PM, Miletich JP, Stampfer MJ, Goldhaber SZ, Lindpaintner K, Hennekens CH. Factor V Leiden and risks of recurrent idiopathic venous thromboembolism. Circulation. 1995;92:2800-2.

28. Perry SL, Ortel TL. Clinical and laboratory evaluation of thrombophilia. Clin Chest Med. 2003;24:153-70.

29. Nizankowska-Mogilnicka E, Adamek L, Grzanka P, Domagala T.B, Sanak M , Krzanowski M, Szczeklik A. Genetic polymorphisms associated with acute pulmonary embolism and deep venous thrombosis. Eur Respir J. 2003;21(1):25-30.

30. Ogzulgen IK, Eim NN , Akar N, Demirel K, Kitapci $\mathrm{M}$. The role of thrombophilic risk factors in the severity of pulmonary embolism. Eur Respir J. 2002;19(4):705-11.

31. Ho WK, Hankey GJ, Quinlan DJ, Eikelboom JW. Risk of recurrent venous thromboembolism in patients with common thrombophilia: a systematic review. Arch Intern Med. 2006;166(7):729-36.

32. Rosendaal FR, Doggen CJ, Zivelin A, Arruda VR, Aiach M, Siscovick DS, et al. Geographic distribution of the $20210 \mathrm{G}$ to A prothrombin variant. Thromb Haemost. 1998;79(4):706-70.

33. De Stefano V, Martinelli I, Mannucci PM, Paciaroni $\mathrm{K}$, Rossi E, Chiusolo $\mathrm{P}$, et al. The risk of recurrent venous thromboembolism among heterozygous carriers of the G20210A prothrombin gene mutation. $\mathrm{Br} \mathrm{J}$ Haematol. 2001;113(3):630-5.

34. Kwak SH, Wang XQ, He Q, Fang WF, Mitra S, Bdeir K, et al. Plasminogen activator inhibitor-1 potentiates LPS-induced neutrophil activation through a JNK-mediated pathway. Thromb Haemost. 2006;95(5):829-35.
35. Pedroja BS, Kang LE, Imas AO, Carmeliet P, Bernstein AM. Plasminogen activator inhibitor-1 regulates integrin alpha $\mathrm{v}$ beta3 expression and autocrine transforming growth factor beta signaling. J Biol Chem. 2009;284(31):20708-17.

36. Abboud N, Ghazouani L, Saidi S, Ben-Hadj-Khalifa S, Addad F, Almawi WY, et al. Association of PAI-1 4G/5G and - 844G/A gene poly-morphisms and changes in PAI-1/tissue plasminogen activator levels in myocardial infarction: a case-control study. Genet Test Mol Biomarkers. 2010;14(1):237.

37. Saidi S, Slamia LB, Mahjoub T, Ammou SB, Almawi WY. Association of PAI-1 4G/5G and 844G/A gene polymorphism and changes in PAI1/tPA levels in stroke: a case-control study. Stroke Cerebrovasc Dis. 2007;16(4):153-9.

38. Tsantes AE, Nikolopoulos GK, Bagos PG, Bonovas $\mathrm{S}$, Kopterides P, Vaiopoulos G. The effect of the plasminogen activator inhibitor- $4 \mathrm{G} / 5 \mathrm{G}$ polymorphism on the thrombotic risk. Thromb Res. 2008;122(6):736-42.

39. Eichinger S, Pabinger I, Stümpflen A, Hirschl M, Bialonczyk C, Schneider B, et al. The risk of recurrent venous thromboembolism in patients with and without factorV Leiden. Thromb Haemost. 1997;77:624-8.

40. Lindmarker P, Schulman S, Sten-Linder M, Wiman B, Egberg N, Johnsson H., et al. The risk of recurrent venous thromboembolism in carriers and non-carriers of the G1691A allele in the coagulation factor $\mathrm{V}$ gene and the G20210A allele in the prothrombin gene. Thromb Haemost. 1999;81:684-9.

41. Simioni P, Prandoni P, Lensing AW, Scudeller A, Sardella C, Prins MH, et al. The risk of recurrent venous thromboembolism in patients with an Arg506 $\rightarrow$ Gln mutation in the gene for factor $V$ (factor V Leiden). N Engl J Med. 1997;336:399403.

42. Optimum duration of anticoagulation for deepvein thrombosis and pulmonary embolism. Research Committee of the British Thoracic Society. Lancet. 1992;340:873-6.

43. Prandoni P, Lensing AW, Cogo A, Cuppini S, Villalta S, Carta M,Cattelan AM, Polistena P, Bernardi E, Prins MH. The long-term clinicalcourse of acute deep venous thrombosis. Ann Intern Med. 1996;125:1-7.

44. Geno J. Merli. Pathophysiology of venous thrombosis, thrombophilia, and the diagnosis of deep vein thrombosis-pulmonaryembolism in the elderly. Clin Geriatr Med. 2006;22:75-92 . 